\title{
Clinical and laboratory parameters associated with acute kidney injury in patients with snakebite envenomation: a prospective observational study from Myanmar
}

Kyi-Phyu Aye ${ }^{1,2}$, Vipa Thanachartwet ${ }^{1 *}$, Chit Soe ${ }^{3}$, Varunee Desakorn ${ }^{1}$, Khin-Thida Thwin ${ }^{4}$, Supat Chamnanchanunt ${ }^{1}$, Duangjai Sahassananda ${ }^{5}$, Thanom Supaporn ${ }^{6}$ and Visith Sitprija ${ }^{7,8}$

\begin{abstract}
Background: Snakebite-related acute kidney injury (AKI) is a common community-acquired AKI in tropical countries leading to death and disability. The aims of this study were to (1) determine the occurrence of snakebite-related AKI, (2) assess factors at presentation that are associated with snakebite-related AKI, and (3) determine the outcomes of patients with snakebite-related AKl.

Methods: We conducted a prospective observational study of patients with snake envenomation at the three academic tertiary care hospitals in Yangon, Myanmar between March 2015 and June 2016. Patient data including baseline characteristics, clinical and laboratory findings, hospital management, and outcomes were recorded in a case report form. A stepwise multivariate logistic regression analysis using a backward selection method determined independent factors significantly associated with AKI.
\end{abstract}

Results: AKI was observed in 140 patients (54.3\%), the majority of whom were AKI stage III (110 patients, 78.6\%). AKI occurred at presentation and developed during hospitalization in 88 (62.9\%) and 52 patients (37.1\%), respectively. Twenty-seven patients died (19.3\%), and 69 patients (49.3\%) required dialysis. On multivariate logistic regression analysis, (1) snakebites from the Viperidae family (odds ratio [OR]: 9.65, 95\% confidence interval [CI]: 2.42-38.44; $p=0.001)$, (2) WBC $>10 \times 10^{3}$ cells/ $\mu \mathrm{L}$ (OR: 3.55, 95\% Cl: 1.35-9.34; $\left.p=0.010\right)$, (3) overt disseminated intravascular coagulation (OR: 2.23, 95\% Cl: 1.02-4.89; $p=0.045)$, (4) serum creatine kinase $>500$ IU/L (OR: 4.06, 95\% Cl: 1.71-9.63; $p=0.001$ ), (5) serum sodium <135 mmol/L (OR: 4.37, 95\% Cl: 2.04-9.38; $p<0.001$ ), (6) presence of microscopic hematuria (OR: $3.60,95 \% \mathrm{Cl}: 1.45-8.91 ; p=0.006$ ), and (7) duration from snakebite to receiving antivenom $\geq 2 \mathrm{~h}$ (OR: $3.73,95 \% \mathrm{Cl}: 1.48-9.37 ; p=0.005)$ were independently associated with AKI. Patients bitten by Viperidae with normal renal function who had serum sodium $<135 \mathrm{mmol} / \mathrm{L}$ had a significantly higher urine sodium-to-creatinine ratio than those with serum sodium $\geq 135 \mathrm{mmol} / \mathrm{L}(p<0.001)$.

Conclusions: Identifying factors associated with snakebite-related AKI might help clinicians to be aware of snakebite patients who are at risk of AKI, particularly patients who demonstrate renal tubular dysfunction after Viperidae bites.

Keywords: Clinical factors, Laboratory factors, Myanmar, Multivariate analysis, Snakebite-related acute kidney injury, Prospective study

\footnotetext{
* Correspondence: vipa.tha@mahidol.edu

'Department of Clinical Tropical Medicine, Faculty of Tropical Medicine,

Mahidol University, Bangkok 10400, Thailand

Full list of author information is available at the end of the article
} 


\section{Background}

Community-acquired acute kidney injury (cAKI) is a major public health problem in tropical countries, particularly in Asia [1, 2]. cAKI in tropical countries commonly affects young adults (age range 37-47 years) without pre-existing comorbidities [2]. These patients are at risk of developing chronic kidney disease [3]. cAKI in tropical countries is usually caused by a single etiology including tropical infections, environmental exposure to a toxin, or occupational risk of snakebite envenomation [1,2]. South Asia, Southeast Asia, and sub-Saharan Africa have the highest burden of snakebite envenomation [4]. In Southeast Asia, envenomation by two families of venomous snakes, Elapidae and Viperidae, are associated with significant morbidity and mortality, with fatality rates of $0.4-20.0 \%[5,6]$. Following snakebite envenomation by snakes of the family Viperidae and Colubridae, patients may develop renal manifestations including proteinuria, hematuria, pigmenturia, and AKI [7, 8].

Snakebite-related AKI (sAKI) is a type of cAKI reported to affect from $8.0-43.0 \%$ of patients with snakebite envenomation [9-15], among whom approximately 15.0-55.0\% required renal replacement therapy (RRT) $[9-11,13]$ and the fatality rate was $8.0-39.0 \%[9-11,13$, 14]. Previous reports from Brazil have shown greater susceptibility to SAKI with increasing age [16, 17]. Reported factors associated with sAKI included age $<12$ years, time from hospitalization to antivenom treatment $>2 \mathrm{~h}$, time from snakebite to receiving antivenom $>2 \mathrm{~h}$, longer duration from snakebite to hospital arrival, cellulitis, regional lymphadenopathy, hypotension, higher total bilirubin level, lower hemoglobin level, intravascular hemolysis, incoagulable blood on 20-min whole blood clotting test (20WBCT), prolonged bleeding time, prolonged prothrombin time (PT), hemorrhagic manifestations, serum creatine kinase $>2000$ IU/L, dark or brown urine color, albuminuria, and longer length of hospitalization $[9,10,12,13,15]$.

A recent report from Myanmar found that approximately 10,000 cases of snakebite occurred annually. Russell's viper was the most common source of envenomation, accounting for $90 \%$ of snakebite cases with the case fatality rate of $10.4 \%$ [18]. Another study from Myanmar showed that approximately $42 \%$ of patients with Russell's viper bites (10 of 24 patients) developed sAKI, all of whom recovered after antivenom treatment, while another $21 \%$ of the snakebite patients (5 of 24) developed sAKI following antivenom treatment [19]. However, data on the renal manifestations and factors associated with the development of sAKI in Myanmar are limited. Overall, the factors associated with sAKI varied across studies due to differences in the study population, potency and composition of snake venom, which differs across geographic regions of the study sites; accessibility of management facilities; and study design [9, 10, 12, 13, 15-17].

Therefore, a prospective observational study was conducted in the three academic tertiary care hospitals in Yangon, Myanmar between March 2015 and June 2016 among patients with snakebite envenomation with the aims to assess (1) the occurrence of sAKI from presentation until discharge, (2) clinical and laboratory factors at presentation that independently associated with the development of sAKI, and (3) outcomes of patients with sAKI. This information might help clinicians to identify patients who are at risk for SAKI in order to provide optimal management for decreasing the incidence of cAKI in tropical countries.

\section{Methods}

\section{Study design and population}

This prospective observational study was conducted at the three academic tertiary care hospitals in Yangon, Myanmar. These hospitals treated the majority of snakebite victims in Yangon and had facilities for laboratory investigations as well as patient care. The procedure indicated by the Standards for the Reporting of Observation Studies in Epidemiology (STROBE) was followed [20]. The study's inclusion criteria were patients at least 12 years old and presenting with clinical parameters of snake envenomation. Patients with (1) a history of underlying medical illness including diabetes mellitus, hypertension, neurological diseases, cardiovascular diseases, renal diseases, pulmonary diseases, liver diseases, and hematologic diseases; (2) receiving any antiplatelet or anticoagulant drugs; or (3) currently pregnant were excluded from this study. All snakebite patients in this study were admitted to the hospitals for observation and management. All patients received standard care by the treating physicians according to the Myanmar National Guidelines, which follow the World Health Organization (WHO) 2010 guidelines for the management of snakebites in Southeast Asian countries [6], with the slight modification of adding 20WBCT monitoring every $2 \mathrm{~h}$ for $12 \mathrm{~h}$, and then $4 \mathrm{~h}$ for $12 \mathrm{~h}$. Neurological symptoms and signs were observed every $30 \mathrm{~min}$ for $12 \mathrm{~h}$, and then hourly for $12 \mathrm{~h}$ in cases of unknown snakebite.

Laboratory parameters including complete blood counts, incoagulable blood on 20WBCT, PT, international normalized ratio (INR), activated partial thromboplastin time (aPTT), fibrinogen level, D-dimer, blood glucose, electrolytes, serum urea, serum creatinine, liver function test, and electrocardiography (ECG) were evaluated at presentation and then as appropriate. Chest X-ray was performed when abnormal lung sounds were detected or upon clinical suspicion of respiratory complications. Urinalysis and spot urine analysis for sodium, potassium, 
protein, and creatinine were also performed at presentation. Spot urine tests for calcium and phosphate were performed when patients demonstrated hypocalcemia and hypophosphatemia, respectively. Spot urine test for magnesium was performed in patients with hypokalemia. Abnormal urine findings and electrolyte abnormalities are defined in Additional file 1: Table S1.

Treatment outcomes including duration of hospitalization, requirement of RRT, and survival status were summarized on discharge. Patient data including baseline characteristics, location where the snakebite occurred, anatomical site of the bite, type of snake, pre-hospital management, clinical parameters, laboratory findings, hospital management, and outcomes were recorded in a pre-defined case report form.

\section{Clinical parameters of envenoming from snakes}

The clinical parameters of both local and systemic envenoming were defined according to the WHO 2010 guidelines for the management of snakebites (Additional file 1: Table S2) [6]. Local bleeding was defined as prolonged bleeding from fang marks, prolonged bleeding from venipuncture site, and/or bleeding from a recent wound. Spontaneous systemic bleeding manifested as skin bleeding (defined as petechiae, purpura, and/or ecchymosis), mucosal bleeding (defined as gum bleeding, hematemesis, melena, hematochezia, gross hematuria, and/or vaginal bleeding), and/or conjunctival bleeding. Hypotension was defined as systolic blood pressure of $<90 \mathrm{mmHg}$ without evidence of tissue hypoperfusion. Capillary leakage was defined as a rise in hematocrit $>2.0 \%$ above the reference range of adults adjusted for sex and serum albumin $<3.0 \mathrm{~g} / \mathrm{dL}$. Disseminated intravascular coagulation (DIC) was diagnosed according to the International Society for Thrombosis and Haemostasis (ISTH) scoring system for DIC, with a score $\geq 5$ considered indicative of overt DIC. The score was calculated based on platelet (PLT) count $\left(\geq 100 \times 10^{3} / \mu \mathrm{L}=0,<100 \times\right.$ $\left.10^{3} / \mu \mathrm{L}=1,<50 \times 10^{3} / \mu \mathrm{L}=2\right) ; \mathrm{D}$-dimer $(<0.5 \mu \mathrm{g} / \mathrm{L}=0,0.5$ to $<1.0 \mu \mathrm{g} / \mathrm{L}=1, \geq 1.0$ to $<2.0 \mu \mathrm{g} / \mathrm{L}=2, \geq 2 \mu \mathrm{g} / \mathrm{L}=3)$; PT $(<15 \mathrm{~s}=0, \geq 15 \mathrm{~s}=1,>20 \mathrm{~s}=2)$; and fibrinogen level $(\geq 100 \mathrm{mg} / \mathrm{dL}=0,<100 \mathrm{mg} / \mathrm{dL}=1)[21]$.

\section{Management of patients with snake envenoming}

Antivenom treatment was indicated when patients developed local envenoming with the clinical signs of (1) local swelling in more than half of the bitten limb (in the absence of a tourniquet) within $48 \mathrm{~h}$ of the bite, (2) rapid extension of swelling over 1 joint within $2 \mathrm{~h}$ of a bite on the hands or feet, and/or (3) development of tender lymphadenitis. Antivenom was also indicated for all cases of systemic envenoming, as indicated by the following: (1) hemostatic abnormalities including spontaneous systemic bleeding, incoagulable blood on 20WBCT, and/or thrombocytopenia defined as PLT count $<100 \times$ $10^{3} / \mu \mathrm{L}$; (2) neurotoxic signs including ptosis, external opthalmoplegia, and/or muscle paralysis; (3) cardiovascular abnormalities including hypotension, shock, and/or abnormal ECG; and/or (4) renal abnormalities including reduced urine volume and/or AKI.

Reduced urine volume was classified as oliguria, defined as $<400 \mathrm{~mL}$ of urine volume in $24 \mathrm{~h}$, or anuria, defined as no urine volume in $24 \mathrm{~h}$. AKI was defined as the increase of serum creatinine $\geq 0.3 \mathrm{mg} / \mathrm{dL}$ within $48 \mathrm{~h}$ or increase in serum creatinine $\geq 1.5$ times baseline. AKI staging was performed according to the Kidney Disease: Improving Global Outcomes (KDIGO) clinical practice guidelines. AKI stage I was defined as serum creatinine increased to 1.5 to 1.9 times baseline. AKI stage II was defined as serum creatinine increased to 2.0 to 2.9 times baseline. AKI stage III was defined as serum creatinine increased to 3.0 times baseline or higher, serum creatinine $\geq 4.0 \mathrm{mg} / \mathrm{dL}$, or receipt of RRT [22]. The dosage of acute peritoneal dialysis was assessed using a weekly $\mathrm{Kt} / \mathrm{V}$ measurement of urea according to the International Society of Peritoneal Dialysis (ISPD) guideline [23]. ' $K$ ' was defined as the volume of dialysate drained multiplied by dialysate/plasma urea concentration, and ' $t$ ' was defined as the duration of dialysis over 1 week. ' $V$ ' was defined as the volume of distribution of urea (total body water $=0.5$ [female] or 0.6 [male] multiplied by body weight).

A specific antivenom treatment was prescribed based on snake identification by well-trained investigators using a handbook of the dangerous venomous snakes of Myanmar [24]. Snake identification was performed if the snake that definitely bit the patient was brought to the hospital either dead or alive for identification or based on the patients' description of the snake to the investigators. If the snake could not be identified, the clinical syndrome of envenoming was considered according to the WHO 2010 guidelines for specific antivenom treatment [6]. The clinical syndrome of Viperidae envenoming consisted of presentation with (1) local envenoming and (2) clinical bleeding and/or incoagulable blood on 20WBCT. The clinical syndrome of Russell's viper envenoming consisted of presentation with (1) local envenoming, (2) clinical bleeding and/or incoagulable blood on 20WBCT, and (3) shock defined by a systolic blood pressure of $<90 \mathrm{mmHg}$ with evidence of tissue hypoperfusion, i.e., $<0.5 \mathrm{~mL} / \mathrm{kg} / \mathrm{h}$ decrease in urine output, cold skin, and/or receipt of inotropic drugs. The clinical syndrome of cobra envenoming consisted of presentation with (1) local envenoming and (2) muscle paralysis.

\section{Sample size calculation}

We estimated the required sample size based on a 2013 study from India, which reported a $15 \%$ rate of AKI 
occurrence among patients with snake envenoming [14]. Based on this data, a minimum of 196 venomous snakebite patients were needed to achieve this rate with 5\% margin of error. We predicted a dropout rate of $20 \%$ during this study; therefore, the required sample size was at least 235 patients.

\section{Statistical analyses}

All data were analyzed using SPSS software (version 18.0; SPSS Inc., Chicago, IL). Numerical variables were tested for normality using the Kolmogorov-Smirnov test. Variables with non-normal distribution were summarized as medians and interquartile ranges (IQRs) and compared using Mann-Whitney $U$ tests for two-group comparisons and Kruskal-Wallis tests for greater than two-group comparisons. A significant result on KruskalWallis tests was subjected to further post-hoc pair-wise comparison by using the Mann-Whitney $U$ test with Bonferroni correction to adjust significance values. Categorical variables were expressed as frequencies and percentages and analyzed using chi-squared or Fisher's exact tests, as appropriate. A univariate logistic regression analysis was used to determine which of the collected baseline characteristics, pre-hospital management, clinical parameters, laboratory findings, and management, were associated with AKI among patients with venomous snakebites. All clinical factors potentially associated with AKI were included in the univariate logistic regression analysis as independent variables, with the occurrence of AKI as the dependent variable. Any variable with a $p$ value $\leq 0.2$ was included in a stepwise multivariate logistic regression analysis using a backward selection method for determining significant independent factors. Linear regression analysis was used to predict urine sodium-to-creatinine ratio from serum sodium and urine potassium-to-creatinine ratio from serum potassium. All tests of significance were two-sided, with a $p$ value $\leq 0.05$ indicating statistical significance.

\section{Results}

A total of 300 patients with snake envenoming were enrolled from the three academic tertiary care hospitals in Yangon, Myanmar between March 2015 and June 2016. Of 300 patients with venomous snakebites, 42 patients were excluded due to a lack of available blood samples (2 patients), receipt of antiplatelet or anticoagulant drugs (3 patients), and history of underlying medical illness (37 patients). Thus, 258 patients with venomous snakebites were ultimately recruited for this study (Fig. 1). Snake identification was possible in 174 patients (67.4\%). Identified snakes included Russell's viper (147 patients, $84.5 \%$ ), cobra (20 patients, $11.5 \%$ ), green pit viper (6 patients, $3.4 \%$ ), and sea snake (1 patient, $0.6 \%$ ). The median (IQR) age of patients with venomous snakebites was 31.0 (23.0-42.0) years, and the majority of patients were male (203 patients, 78.7\%). Renal manifestations among patients with venomous snakebites at presentation are shown in Table 1 . Of 128 patients with reduced urine volume, $112(87.5 \%)$ patients presented with oliguria, and 16 (12.5\%) patients presented with anuria. Of 140 patients with AKI, $88(62.9 \%)$ had AKI at presentation, and 52 (37.1\%) developed AKI during hospitalization. Among the 52 patients who developed AKI during hospitalization, 48 (92.3\%) developed AKI within $48 \mathrm{~h}$ of hospitalization, and the remaining $4(7.7 \%)$ developed AKI after $48 \mathrm{~h}$ of hospitalization. AKI stages I and II were observed in 15 (10.7\%) patients each, and AKI stage III was observed in 110 patients (78.6\%). Thus, the 258 patients with venomous snakebites included 140 (54.3\%) patients with AKI and 118 (45.7\%) patients without AKI (Fig. 1).

\section{Comparison of baseline characteristics, pre-hospital management, clinical, and laboratory parameters between patients with and without AKI}

Baseline characteristics and pre-hospital management are shown in Additional file 1: Table S3. Most baseline characteristics were similar, except that the rates of patients living in Yangon city or being bitten in the field,

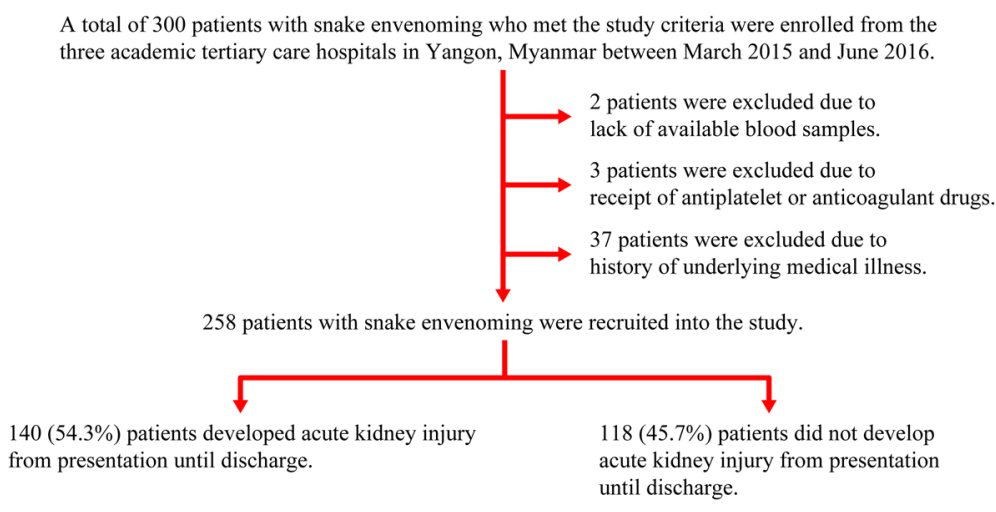

Fig. 1 Flow diagram showing the recruitment of study patients 
Table 1 Renal manifestations among 258 adults with snakebite envenomation, Yangon, Myanmar, 2015-2016

\begin{tabular}{|c|c|c|}
\hline Characteristic & All & $n(\%)$ \\
\hline \multicolumn{3}{|l|}{ Clinical manifestations } \\
\hline Reduced urine volume & 258 & $128(49.6)$ \\
\hline Renal tenderness & 258 & $114(44.2)$ \\
\hline Gross hematuria & 258 & $46(17.8)$ \\
\hline Dark-colored urine & 258 & $25(9.7)$ \\
\hline \multicolumn{3}{|l|}{ Urinalysis and urine chemistries } \\
\hline Urine protein-to-creatinine ratio $\geq 1$ & 186 & $112(60.2)$ \\
\hline Microscopic hematuria & 255 & $81(31.4)$ \\
\hline Pigmenturia & 255 & $38(14.7)$ \\
\hline Leukocyturia & 255 & $22(8.5)$ \\
\hline \multicolumn{3}{|l|}{ Blood chemistry } \\
\hline Acute kidney injury & 258 & $140(54.3)$ \\
\hline At presentation & 140 & $88(62.9)$ \\
\hline During hospitalization & 140 & $52(37.1)$ \\
\hline \multicolumn{3}{|l|}{ Serum sodium } \\
\hline Hyponatremia & 258 & $115(44.6)$ \\
\hline Hypernatremia & 258 & $5(1.9)$ \\
\hline \multicolumn{3}{|l|}{ Serum potassium } \\
\hline Hypokalemia & 258 & $52(20.2)$ \\
\hline Hyperkalemia & 258 & $19(7.4)$ \\
\hline \multicolumn{3}{|l|}{ Serum calcium } \\
\hline Hypocalcemia & 256 & $88(34.4)$ \\
\hline Hypercalcemia & 256 & $6(2.3)$ \\
\hline \multicolumn{3}{|l|}{ Serum phosphate } \\
\hline Hypophosphatemia & 256 & $20(7.8)$ \\
\hline Hyperphosphatemia & 256 & $68(26.6)$ \\
\hline \multicolumn{3}{|l|}{ Serum bicarbonate } \\
\hline Metabolic acidosis & 258 & $22(8.5)$ \\
\hline Metabolic alkalosis & 258 & $1(0.4)$ \\
\hline
\end{tabular}

on the lower extremities, by a snake of the Viperidae family, or presenting with the clinical syndrome of Viperidae envenoming (all $p<0.001$ ) were more likely to develop AKI. Most pre-hospital management characteristics were also similar between the groups, except that tourniquet application $(p=0.015)$ and receipt of management by a traditional healer $(p=0.048)$ were associated with the development of AKI.

Clinical presentations that were associated with the development of AKI included tender lymphadenitis, local swelling grades II to IV, bruising, vomiting, muscle pain, abdominal pain, abnormal ECG, hypotension, shock, conjunctival edema, pulmonary edema, systemic bleeding, reduced urine volume, renal tenderness, puffy eyelids (all $p<0.001)$, and dark-colored urine $(p=0.003)$ (Additional file 1: Table S4). Laboratory findings at presentation are shown in Additional file 1: Table S5. Patients with AKI had significantly higher WBC counts and neutrophil levels (both $p<0.001)$, PT $(p=0.036)$, INR $(p=0.019)$, aPTT $(p=0.005)$, fibrinogen $(p=0.013)$, D-dimer $(p<0.001)$, blood sugar $(p=0.002)$, serum urea, serum creatinine, serum potassium, serum phosphate, serum creatine kinase, AST, ALT, urine protein-tocreatinine ratio, and fractional excretion of sodium (all $p<0.001)$. In addition, there were significantly higher numbers of patients with incoagulable blood on 20WBCT and microscopic hematuria (all $p<0.001$ ) among those who developed AKI. However, patients with AKI had significantly lower lymphocyte level, PLT count, serum sodium, serum chloride, serum bicarbonate, serum calcium, albumin, and fractional excretion of urea (all $p=0.001$ ). When laboratory findings were categorized based on reference ranges, a significantly higher proportion of patients with WBC count $>10 \times 10^{3}$ cells/ $\mu \mathrm{L}(p<0.001)$, overt DIC $(p<0.001)$, presence of capillary leakage $(p<0.001)$, serum creatine kinase $>500 \mathrm{IU} / \mathrm{L}$ $(p<0.001)$, blood sugar $\geq 150 \mathrm{mg} / \mathrm{dL} \quad(p=0.017)$, and serum sodium $<135 \mathrm{mmol} / \mathrm{L}(p<0.001)$ developed AKI. Potential factors related to the development of AKI including clinical and laboratory parameters are summarized in Table 2. For any potential factors that had multi-collinearity with each other, only one appropriate factor was chosen.

Urine protein-to-creatinine ratio in relation to AKI staging or the absence of AKI was also evaluated. A significant different in median urine protein-to-creatinine ratio was observed among the groups (Kruskal-Wallis test, chi-squared $=66.572$, degrees of freedom $=3, p<0.001$ ). Post-hoc analysis by Mann-Whitney $U$ test with Bonferroni correction showed that the median (IQR) urine protein-to-creatinine ratio of patients without AKI (0.14 [0.03-0.65]) was significantly lower than those of patients with AKI stage I (2.47 [0.71-7.51], $p=0.001)$, AKI stage II (6.66 [2.24-10.39], $p<0.001)$, and AKI stage III (5.83 [1.15-34.41], $p<0.001)$. However, urine protein-to-creatinine ratio did not significantly differ among patients with AKI stage I, II, or III (Fig. 2).

\section{Comparison of management and outcomes among patients with and without AKI}

The management and outcomes of patients with and without AKI are shown in Additional file 1: Table S6. A significantly higher proportion of patients with AKI had a duration from snakebite to hospital of $\geq 1 \mathrm{~h}(p=0.037)$ and had a duration from snakebite to receipt of antivenom of $\geq 2 \mathrm{~h}(p=0.007)$. Patients with AKI received a significantly higher total dose of antivenom treatment $(p<0.001)$. The proportion of patients who received monovalent or polyvalent antivenom treatment was similar in both groups. Significantly higher proportions 
Table 2 Clinical parameters, laboratory findings, and management characteristics among 258 adults with snakebite envenomation, Yangon, Myanmar, 2015-2016

\begin{tabular}{|c|c|c|c|c|}
\hline Characteristics & All & With acute kidney injury, $n$ (\%) & Without acute kidney injury, $n(\%)$ & $p$ value \\
\hline \multicolumn{5}{|l|}{ Clinical parameters } \\
\hline \multicolumn{5}{|c|}{$\begin{array}{l}\text { Bites from Viperidae or presenting the clinical } \\
\text { syndrome of Viperidae }\end{array}$} \\
\hline Yes & 214 & $136(63.6)$ & $78(36.4)$ & \multirow[t]{2}{*}{$<0.001$} \\
\hline No & 44 & $4(9.1)$ & $40(90.9)$ & \\
\hline \multicolumn{5}{|l|}{ Local swelling } \\
\hline Grades II-IV & 167 & $111(66.5)$ & $56(33.5)$ & \multirow[t]{2}{*}{$<0.001$} \\
\hline Grades 0-I & 91 & 29 (31.9) & $62(68.1)$ & \\
\hline \multicolumn{5}{|l|}{ Hypotension } \\
\hline Yes & 69 & $60(87.0)$ & $9(13.0)$ & \multirow[t]{2}{*}{$<0.001$} \\
\hline No & 189 & $80(42.3)$ & $109(57.7)$ & \\
\hline \multicolumn{5}{|c|}{ Laboratory parameters } \\
\hline \multicolumn{5}{|l|}{ WBC (cells/ $\mu \mathrm{L})$} \\
\hline$>10 \times 10^{3}$ & 194 & $126(64.9)$ & $68(35.1)$ & \multirow[t]{2}{*}{$<0.001$} \\
\hline$\leq 10 \times 10^{3}$ & 64 & $14(21.9)$ & $50(78.1)$ & \\
\hline \multicolumn{5}{|l|}{ Overt DIC } \\
\hline Yes & 147 & $103(70.1)$ & $44(29.9)$ & \multirow[t]{2}{*}{$<0.001$} \\
\hline No & 111 & $37(33.3)$ & $74(66.7)$ & \\
\hline \multicolumn{5}{|l|}{ Capillary leakage } \\
\hline Yes & 35 & $30(85.7)$ & $5(14.3)$ & \multirow[t]{2}{*}{$<0.001$} \\
\hline No & 223 & $110(49.3)$ & $113(50.7)$ & \\
\hline \multicolumn{5}{|c|}{ Creatine kinase (IU/L) } \\
\hline$>500$ & 104 & $87(83.7)$ & $17(16.3)$ & \multirow[t]{2}{*}{$<0.001$} \\
\hline$\leq 500$ & 152 & $51(33.6)$ & $101(66.4)$ & \\
\hline \multicolumn{5}{|c|}{ Blood sugar (mg/dL) } \\
\hline$\geq 150$ & 53 & $37(69.8)$ & $16(30.2)$ & \multirow[t]{2}{*}{0.017} \\
\hline$<150$ & 205 & $103(50.2)$ & $102(49.8)$ & \\
\hline \multicolumn{5}{|c|}{ Serum sodium (mmol/L) } \\
\hline$<135 \mathrm{mmol} / \mathrm{L}$ & 115 & $91(79.1)$ & $24(20.9)$ & \multirow[t]{2}{*}{$<0.001$} \\
\hline$\geq 135 \mathrm{mmol} / \mathrm{L}$ & 143 & $49(34.3)$ & $94(65.7)$ & \\
\hline \multicolumn{5}{|c|}{ Microscopic hematuria } \\
\hline Yes & 81 & $70(86.4)$ & $11(13.6)$ & \multirow[t]{2}{*}{$<0.001$} \\
\hline No & 174 & $67(38.5)$ & $107(61.5)$ & \\
\hline \multicolumn{5}{|l|}{ Management } \\
\hline \multicolumn{5}{|c|}{ Site of management } \\
\hline Ward & 211 & $129(61.1)$ & $82(38.9)$ & \multirow[t]{2}{*}{$<0.001$} \\
\hline ICU & 47 & $11(23.4)$ & $36(76.6)$ & \\
\hline \multicolumn{5}{|c|}{ Time from bite to receiving antivenom (hours) } \\
\hline$\geq 2$ & 174 & $107(61.5)$ & $67(38.5)$ & \multirow[t]{2}{*}{0.007} \\
\hline$<2$ & 76 & $32(42.1)$ & $44(57.9)$ & \\
\hline
\end{tabular}

Abbreviations: DIC disseminated intravascular coagulation, ICU intensive care unit, WBC white blood cell, 20WBCT 20-min whole blood clotting test

of patients with AKI received antibiotics at admission, received inpatient treatment on a hospital ward, received inotropic drugs (all $p<0.001$ ), and developed panhypopituitarism $(p=0.004)$. The potential management characteristics related to the development of AKI are shown in Table 2. Regarding patient outcomes, 


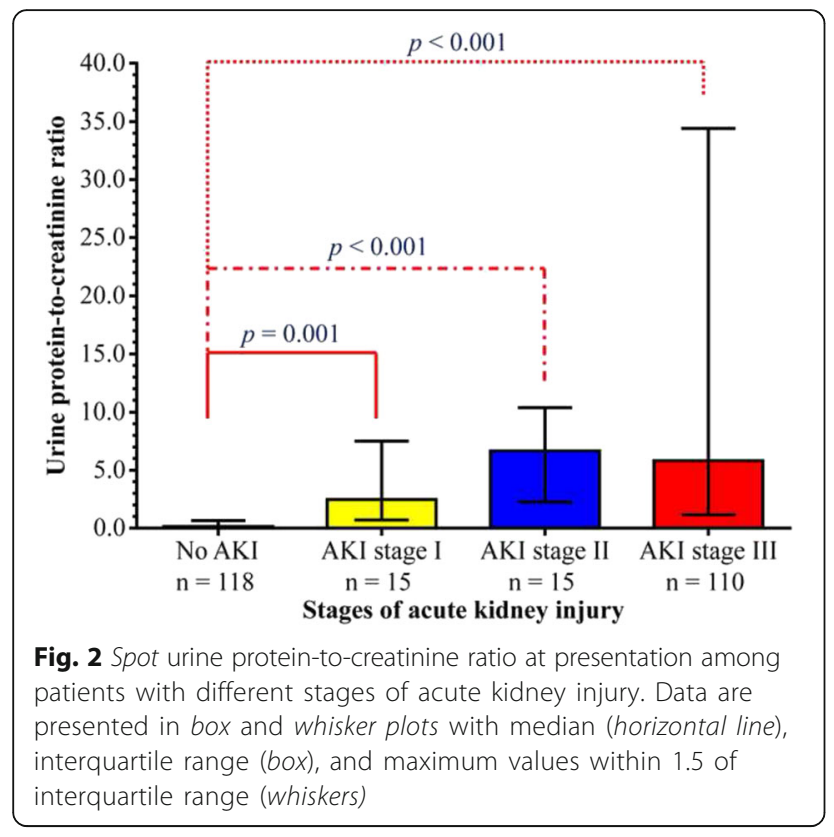

patients with AKI had a significantly longer duration of hospitalization, greater requirement for RRT, and higher mortality rate (all $p<0.001$ ).

Of 140 patients with AKI, 27 (19.3\%) died, and 113 $(80.7 \%)$ survived. Clinical parameters and management of deceased and surviving patients with AKI are shown in Table 3. Patients who died were more likely to develop shock, receive inotropic drugs, and demonstrate acute respiratory distress syndrome (ARDS) or respiratory failure (all $p<0.001$ ). Of 140 patients with AKI, 69 (49.3\%) required RRT. The indications for dialysis included uremia in 39 patients $(56.5 \%)$, severe metabolic acidosis in 15 (21.7\%), fluid overload in 9 (13.0\%), and severe hyperkalemia in $6(8.7 \%)$. The proportions of patients who required RRT were similar between those who died and those who survived. Acute peritoneal dialysis was performed in 62 patients who required RRT (89.8\%), and the remaining 7 patients $(10.2 \%)$ received hemodialysis. The methods of dialysis used in both groups were similar $(p=0.118)$. Weekly $\mathrm{Kt} / \mathrm{V}$ was evaluated in only 52 patients who received acute peritoneal dialysis, including 8 patients (15.4\%) who died and 44 (84.6\%) who survived. The median (IQR) weekly $\mathrm{Kt} / \mathrm{V}$ was similar in both groups $(1.9[1.1-3.0]$ vs. 2.7 [2.2-3.9], $p=0.116)$.

\section{Univariate and multivariate analyses for identifying factors associated with AKI among patients with venomous snakebites}

Using a univariate logistic regression model, the following clinical parameters were associated with AKI: snakebites of the family Viperidae or presenting the clinical syndrome of Viperidae envenoming, local swelling of grades II to IV, presence of hypotension, WBC count $>10 \times 10^{3}$ cells $/ \mu \mathrm{L}$, overt DIC, presence of capillary leakage, serum creatine kinase $>500 \mathrm{IU} / \mathrm{L}$, blood sugar $\geq 150 \mathrm{mg} / \mathrm{dL}$, serum sodium $<135 \mathrm{mmol} / \mathrm{L}$, presence of microscopic hematuria, management on a ward, and duration from bite to receipt of antivenom $\geq 2 \mathrm{~h}$ (Table 4).

In a multivariate logistic regression model, the following clinical and laboratory parameters were independently associated with AKI: snakebites of the family Viperidae or presenting the clinical syndrome of Viperidae envenoming (odds ratio [OR]: 9.65; 95\% CI: $2.42-$ $38.44 ; p=0.001)$, WBC count $>10 \times 10^{3}$ cells $/ \mu \mathrm{L}(\mathrm{OR}$ : 3.55, 95\% CI: $1.35-9.34 ; p=0.010$ ), overt DIC (OR: 2.23 , 95\% CI: $1.02-4.89 ; p=0.045)$, serum creatine kinase $>500$ IU/L (OR: 4.06, 95\% CI: 1.71-9.63; $p=0.001$ ), serum sodium <135 mmol/L (OR: 4.37, 95\% CI: $2.04-$ 9.38; $p<0.001$ ), presence of microscopic hematuria (OR: 3.60, 95\% CI: 1.45-8.91; $p=0.006$ ), and duration from snakebite to receipt of antivenom $\geq 2 \mathrm{~h}$ (OR: $3.73,95 \%$ CI: 1.48-9.37; $p=0.005$ ) (Table 4).

Table 3 Clinical parameters and management among 140 adults with acute kidney injury (deceased and survivors)

\begin{tabular}{|c|c|c|c|c|c|}
\hline \multirow[t]{2}{*}{ Characteristics } & \multicolumn{2}{|c|}{ Deceased } & \multicolumn{2}{|c|}{ Survivors } & \multirow[t]{2}{*}{$p$ value } \\
\hline & All & $n(\%)$ & All & $n(\%)$ & \\
\hline Time from bite to hospital $\geq 1 \mathrm{~h}$ & 27 & $24(88.9)$ & 113 & $91(80.5)$ & 0.408 \\
\hline Time from bite to receiving antivenom $\geq 2 \mathrm{~h}$ & 27 & $21(77.8)$ & 112 & $86(76.8)$ & 1.000 \\
\hline Management in ICU & 27 & $7(25.9)$ & 113 & $4(3.5)$ & 0.001 \\
\hline Shock & 27 & $20(74.1)$ & 113 & $34(30.1)$ & $<0.001$ \\
\hline Received inotropic drugs & 27 & $20(74.1)$ & 113 & $23(20.4)$ & $<0.001$ \\
\hline ARDS or respiratory failure & 27 & $13(48.1)$ & 113 & $9(8.0)$ & $<0.001$ \\
\hline Required renal replacement therapy & 27 & $13(48.1)$ & 113 & $56(49.6)$ & 1.000 \\
\hline Received peritoneal dialysis & 13 & $10(76.9)$ & 56 & $52(92.9)$ & 0.118 \\
\hline Weekly Kt/v, median (IQR) & 8 & $1.9(1.1-3.0)$ & 44 & $2.7(2.2-3.9)$ & 0.116 \\
\hline
\end{tabular}


Table 4 Logistic regression analysis of parameters associated with acute kidney injury, Yangon, Myanmar, 2015-2016

\begin{tabular}{|c|c|c|c|c|c|c|}
\hline \multirow[t]{2}{*}{ Characteristic } & \multicolumn{3}{|c|}{ Univariate analysis } & \multicolumn{3}{|c|}{ Multivariate analysis } \\
\hline & $n$ & OR $(95 \% \mathrm{Cl})$ & $p$ value & $n$ & OR $(95 \% \mathrm{Cl})$ & $p$ value \\
\hline \multicolumn{7}{|l|}{ Clinical parameters } \\
\hline $\begin{array}{l}\text { Bites from Viperidae or presenting clinical } \\
\text { syndrome of Viperidae }\end{array}$ & 258 & & & 244 & & \\
\hline Yes & & $17.44(6.01-50.57)$ & $<0.001$ & & $9.65(2.42-38.44)$ & 0.001 \\
\hline No & & 1.00 (Reference) & & & 1.00 (Reference) & \\
\hline Local swelling & 258 & & & & & \\
\hline Grades II-IV & & $4.24(2.45-7.31)$ & $<0.001$ & & & \\
\hline Grades 0-I & & 1.00 (Reference) & & & & \\
\hline Hypotension & 258 & & & & & \\
\hline Yes & & $9.08(4.26-19.38)$ & $<0.001$ & & & \\
\hline No & & 1.00 (Reference) & & & & \\
\hline \multicolumn{7}{|l|}{ Laboratory parameters } \\
\hline 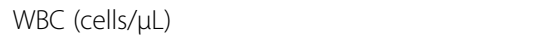 & 258 & & & 244 & & \\
\hline$>10 \times 10^{3}$ & & $6.62(3.41-12.83)$ & $<0.001$ & & $3.55(1.35-9.34)$ & 0.010 \\
\hline$\leq 10 \times 10^{3}$ & & 1.00 (Reference) & & & 1.00 (Reference) & \\
\hline Overt DIC & 258 & & & 244 & & \\
\hline Yes & & $4.68(2.76-7.95)$ & $<0.001$ & & $2.23(1.02-4.89)$ & 0.045 \\
\hline No & & 1.00 (Reference) & & & 1.00 (Reference) & \\
\hline Capillary leakage & 258 & & & & & \\
\hline Yes & & $6.16(2.31-16.46)$ & $<0.001$ & & & \\
\hline No & & 1.00 (Reference) & & & & \\
\hline Creatine kinase (IU/L) & 256 & & & 244 & & \\
\hline$>500$ & & $10.14(5.46-18.83)$ & $<0.001$ & & $4.06(1.71-9.63)$ & 0.001 \\
\hline$\leq 500$ & & 1.00 (Reference) & & & 1.00 (Reference) & \\
\hline Blood sugar (mg/dL) & 258 & & & & & \\
\hline$\geq 150$ & & $2.29(2.00-4.37)$ & 0.012 & & & \\
\hline$<150$ & & 1.00 (Reference) & & & & \\
\hline Serum sodium (mmol/L) & 258 & & & 244 & & \\
\hline$<135 \mathrm{mmol} / \mathrm{L}$ & & $7.27(4.13-12.82)$ & $<0.001$ & & $4.37(2.04-9.38)$ & $<0.001$ \\
\hline$\geq 135 \mathrm{mmol} / \mathrm{L}$ & & 1.00 (Reference) & & & 1.00 (Reference) & \\
\hline Microscopic hematuria & 255 & & & 244 & & \\
\hline Yes & & $10.16(5.02-20.57)$ & $<0.001$ & & $3.60(1.45-8.91)$ & 0.006 \\
\hline No & & 1.00 (Reference) & & & 1.00 (Reference) & \\
\hline \multicolumn{7}{|l|}{ Management } \\
\hline Site of management & 258 & & & & & \\
\hline Ward & & $5.15(2.48-10.68)$ & $<0.001$ & & & \\
\hline ICU & & 1.00 (Reference) & & & & \\
\hline Time from bite to receiving antivenom (hours) & 250 & & & 244 & & \\
\hline$\geq 2$ & & $2.20(1.27-3.80)$ & 0.005 & & $3.73(1.48-9.37)$ & 0.005 \\
\hline$<2$ & & 1.00 (Reference) & & & 1.00 (Reference) & \\
\hline
\end{tabular}

Abbreviations: $\mathrm{Cl}$ confidence interval, DIC disseminated intravascular coagulation, ICU intensive care unit, $O R$ odds ratio, WBC white blood cell 
Subgroup analysis for identifying factors associated with AKI at presentation and during hospitalization among patients bitten by Viperidae or presenting the clinical syndrome of Viperidae

AKI is a common complication after snakebite envenomation from members of the Viperidae family [5-8]. Thus, factors associated with AKI at presentation and during hospitalization among patients bitten by Viperidae or presenting the clinical syndrome of Viperidae envenoming were identified in this study. Of 214 patients bitten by Viperidae or presenting the clinical syndrome of Viperidae envenoming, 136 (63.6\%) developed AKI, including 86 patients (63.2\%) with AKI at presentation and 50 (36.8\%) who developed AKI during hospitalization. The remaining 78 patients $(36.4 \%)$ did not develop AKI. Of the 50 patients who developed AKI during hospitalization, 47 (94.0\%) developed AKI within
$48 \mathrm{~h}$ of hospitalization and the remaining 3 patients (6.0\%) developed AKI after $48 \mathrm{~h}$ of hospitalization.

Comparisons of clinical parameters, laboratory findings, management, and outcomes between the 86 patients with AKI at presentation and 78 patients without AKI are shown in Additional file 1: Tables S7, S8, and S9. Clinical parameters, laboratory findings, and management characteristics possibly affecting renal function are shown in Table 5 . Patients with the parameters of presence of hypotension $(p<0.001)$, WBC count $>10 \times 10^{3}$ cells $/ \mu \mathrm{L}(p<0.001)$, overt DIC $(p<0.001)$, presence of capillary leakage $(p=0.001)$, serum creatine kinase $>500 \mathrm{IU} /$ $\mathrm{L}(p<0.001)$, blood sugar $\geq 150 \mathrm{mg} / \mathrm{dL}(p=0.015)$, serum sodium $<135 \mathrm{mmol} / \mathrm{L}(p<0.001)$, presence of microscopic hematuria $(p<0.001)$, and duration from snakebite to receipt of antivenom $\geq 2 \mathrm{~h}(p=0.021)$ were more likely to develop AKI at presentation (Table 5).

Table 5 Clinical parameters, laboratory findings, and management characteristics of 164 adults bitten by Viperidae or presenting the clinical syndrome of Viperidae (86 patients with acute kidney injury at presentation and 78 patients without acute kidney injury)

\begin{tabular}{|c|c|c|c|c|}
\hline Characteristics & All & With acute kidney injury, $n$ (\%) & Without acute kidney injury, $n$ (\%) & $p$ value \\
\hline \multicolumn{5}{|l|}{ Hypotension } \\
\hline Yes & 46 & $39(84.8)$ & $7(15.2)$ & \multirow[t]{2}{*}{$<0.001$} \\
\hline No & 118 & $47(39.8)$ & $71(60.2)$ & \\
\hline \multicolumn{5}{|l|}{ WBC (cells/ $\mu \mathrm{L})$} \\
\hline$>10 \times 10^{3}$ & 122 & $75(61.5)$ & $47(38.5)$ & \multirow[t]{2}{*}{$<0.001$} \\
\hline$\leq 10 \times 10^{3}$ & 41 & $10(24.4)$ & $31(75.6)$ & \\
\hline \multicolumn{5}{|l|}{ Overt DIC } \\
\hline Yes & 100 & $64(64.0)$ & $36(36.0)$ & \multirow[t]{2}{*}{$<0.001$} \\
\hline No & 64 & $22(34.4)$ & $42(65.6)$ & \\
\hline \multicolumn{5}{|l|}{ Capillary leakage } \\
\hline Yes & 19 & $17(89.5)$ & $2(10.5)$ & \multirow[t]{2}{*}{0.001} \\
\hline No & 145 & 69 (47.6) & $76(52.4)$ & \\
\hline \multicolumn{5}{|c|}{ Creatine kinase (IU/L) } \\
\hline$>500$ & 69 & $57(82.6)$ & $12(17.4)$ & \multirow[t]{2}{*}{$<0.001$} \\
\hline$\leq 500$ & 95 & $29(30.5)$ & $66(69.5)$ & \\
\hline \multicolumn{5}{|c|}{ Blood sugar (mg/dL) } \\
\hline$\geq 150$ & 38 & $27(71.1)$ & $11(28.9)$ & \multirow[t]{2}{*}{0.015} \\
\hline$<150$ & 126 & $59(46.8)$ & $67(53.2)$ & \\
\hline \multicolumn{5}{|c|}{ Serum sodium (mmol/L) } \\
\hline$<135$ & 77 & $61(79.2)$ & $16(20.8)$ & \multirow[t]{2}{*}{$<0.001$} \\
\hline$\geq 135$ & 87 & $25(28.7)$ & $62(71.3)$ & \\
\hline \multicolumn{5}{|c|}{ Microscopic hematuria } \\
\hline Yes & 61 & $51(83.6)$ & $10(16.4)$ & \multirow[t]{2}{*}{$<0.001$} \\
\hline No & 101 & $33(32.7)$ & $68(67.3)$ & \\
\hline \multicolumn{5}{|c|}{ Time from bite to receiving antivenom (hours) } \\
\hline$\geq 2$ & 112 & $68(60.7)$ & $44(39.3)$ & \multirow[t]{2}{*}{0.021} \\
\hline$<2$ & 44 & $17(38.6)$ & $27(61.4)$ & \\
\hline
\end{tabular}


These parameters were also associated with AKI at presentation using a univariate logistic regression model (Table 6). In a multivariate logistic regression model, the following clinical and laboratory parameters were independently associated with AKI at presentation: presence of hypotension (odds ratio [OR]: 3.56; 95\% CI: 1.0512.09; $p=0.042)$, serum creatine kinase $>500$ IU/L (OR: $6.24,95 \%$ CI: $2.10-18.49 ; p=0.001)$, serum sodium $<135 \mathrm{mmol} / \mathrm{L}$ (OR: 7.81, 95\% CI: 2.87-21.24; $p<0.001$ ), presence of microscopic hematuria (OR: 11.45 , 95\% CI: $3.76-34.82 ; p<0.001)$, and duration from snakebite to receipt of antivenom $\geq 2 \mathrm{~h}$ (OR: 7.98, 95\% CI: $2.06-$ 30.92; $p=0.003$ ) (Table 6).

Comparison of clinical parameters, laboratory findings, management characteristics, and outcomes among
50 patients with AKI during hospitalization and 78 patients without AKI are shown in Additional file 1: Tables S10, S11, and S12. Clinical parameters, laboratory findings, and management characteristics possibly affecting renal function are shown in Table 7. Patients with the parameters of overt DIC $(p=0.007)$, presence of capillary leakage $(p<0.001)$, serum creatine kinase $>500 \mathrm{IU} / \mathrm{L}(p<0.001)$, serum sodium $<135 \mathrm{mmol} / \mathrm{L}$ $(p<0.001)$, and who received a total dose of antivenom $>160 \mathrm{~mL}(p=0.016)$ were more likely to develop AKI during hospitalization (Table 7).

These parameters were also found to be associated with AKI during hospitalization using a univariate logistic regression model (Table 8 ). In a multivariate logistic regression model, the following parameters were

Table 6 Univariate and multivariate analysis of clinical and laboratory parameters of adults bitten by Viperidae or presenting the clinical syndrome of Viperidae for identifying acute kidney injury at presentation

\begin{tabular}{|c|c|c|c|c|c|c|}
\hline \multirow[t]{2}{*}{ Characteristic } & \multicolumn{3}{|c|}{ Univariate analysis } & \multicolumn{3}{|c|}{ Multivariate analysis } \\
\hline & $n$ & OR $(95 \% \mathrm{Cl})$ & $p$ value & $n$ & OR $(95 \% \mathrm{Cl})$ & $p$ value \\
\hline Hypotension & 164 & & & 153 & & \\
\hline Yes & & $8.42(3.47-20.39)$ & $<0.001$ & & $3.56(1.05-12.09)$ & 0.042 \\
\hline No & & 1.00 (Reference) & & & 1.00 (Reference) & \\
\hline 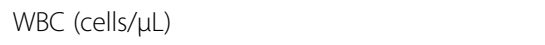 & 163 & & & & & \\
\hline$>10 \times 10^{3}$ & & $4.95(2.22-11.02)$ & $<0.001$ & & & \\
\hline$\leq 10 \times 10^{3}$ & & 1.00 (Reference) & & & & \\
\hline Overt DIC & 164 & & & & & \\
\hline Yes & & $3.39(1.76-6.55)$ & $<0.001$ & & & \\
\hline No & & 1.00 (Reference) & & & & \\
\hline Capillary leakage & 164 & & & & & \\
\hline Yes & & $9.36(2.09-42.00)$ & 0.003 & & & \\
\hline No & & 1.00 (Reference) & & & & \\
\hline Creatine kinase (IU/L) & 164 & & & 153 & & \\
\hline$>500$ & & $10.81(5.05-23.12)$ & $<0.001$ & & $6.24(2.10-18.49)$ & 0.001 \\
\hline$\leq 500$ & & 1.00 (Reference) & & & 1.00 (Reference) & \\
\hline Blood sugar (mg/dL) & 164 & & & & & \\
\hline$\geq 150$ & & $2.79(1.27-6.10)$ & 0.010 & & & \\
\hline$<150$ & & 1.00 (Reference) & & & & \\
\hline Serum sodium (mmol/L) & 164 & & & 153 & & \\
\hline$<135 \mathrm{mmol} / \mathrm{L}$ & & $9.46(4.60-19.43)$ & $<0.001$ & & $7.81(2.87-21.24)$ & $<0.001$ \\
\hline$\geq 135 \mathrm{mmol} / \mathrm{L}$ & & 1.00 (Reference) & & & 1.00 (Reference) & \\
\hline Microscopic hematuria & 162 & & & 153 & & \\
\hline Yes & & $10.51(4.74-23.28)$ & $<0.001$ & & $11.45(3.76-34.82)$ & $<0.001$ \\
\hline No & & 1.00 (Reference) & & & 1.00 (Reference) & \\
\hline Time from bite to receiving antivenom (hours) & 156 & & & 153 & & \\
\hline$\geq 2$ & & $2.45(1.20-5.02)$ & 0.014 & & $7.98(2.06-30.92)$ & 0.003 \\
\hline$<2$ & & 1.00 (Reference) & & & 1.00 (Reference) & \\
\hline
\end{tabular}


Table 7 Clinical parameters, laboratory findings, and management characteristics of 128 adults bitten by Viperidae or presenting the clinical syndrome of Viperidae (50 patients who developed acute kidney injury during hospitalization and 78 patients without acute kidney injury)

\begin{tabular}{|c|c|c|c|c|}
\hline Characteristics & All & With acute kidney injury, $n$ (\%) & Without acute kidney injury, $n(\%)$ & $p$ value \\
\hline \multicolumn{5}{|l|}{ Overt DIC } \\
\hline Yes & 72 & $36(50.0)$ & $36(50.0)$ & \multirow[t]{2}{*}{0.007} \\
\hline No & 56 & $14(25.0)$ & $42(75.0)$ & \\
\hline \multicolumn{5}{|c|}{ Capillary leakage } \\
\hline Yes & 14 & $12(85.7)$ & $2(14.3)$ & \multirow[t]{2}{*}{$<0.001$} \\
\hline No & 114 & $38(33.3)$ & $76(66.7)$ & \\
\hline \multicolumn{5}{|c|}{ Creatine kinase (IU/L) } \\
\hline$>500$ & 40 & $28(70.0)$ & $12(30.0)$ & \multirow[t]{2}{*}{$<0.001$} \\
\hline$\leq 500$ & 86 & $20(23.3)$ & $66(76.7)$ & \\
\hline \multicolumn{5}{|c|}{ Serum sodium (mmol/L) } \\
\hline$<135$ & 45 & $29(64.4)$ & $16(35.6)$ & \multirow[t]{2}{*}{$<0.001$} \\
\hline$\geq 135$ & 83 & $21(25.3)$ & $62(74.7)$ & \\
\hline \multicolumn{5}{|c|}{ Total dose of antivenom (mL) } \\
\hline$>160$ & 31 & $19(61.3)$ & $12(38.7)$ & \multirow[t]{2}{*}{0.016} \\
\hline$\leq 160$ & 90 & $31(34.4)$ & $59(65.6)$ & \\
\hline
\end{tabular}

Abbreviation: DIC disseminated intravascular coagulation

independently associated with AKI during hospitalization: presence of capillary leakage (odds ratio [OR]: 6.30; 95\% CI: $1.13-35.22 ; p=0.036)$, serum creatine kinase $>500$ IU/L (OR: 4.80, 95\% CI: 1.86-12.37; $p=0.001$ ), and serum sodium $<135 \mathrm{mmol} / \mathrm{L}$ (OR: $4.27,95 \% \mathrm{CI}$ : $1.74-10.45 ; p=0.001)$ (Table 8).

\section{Evaluation of electrolyte abnormalities among patients with normal renal function at presentation}

In our study, electrolyte abnormalities, particularly hyponatremia (serum sodium $<135 \mathrm{mmol} / \mathrm{L}$ ) and hypokalemia (serum potassium $<3.5 \mathrm{mmol} / \mathrm{L}$ ), were common renal manifestations among the 258 patients with snake

Table 8 Univariate and multivariate analysis of clinical and laboratory parameters of adults bitten by Viperidae or presenting the clinical syndrome of Viperidae for identifying acute kidney injury during hospitalization

\begin{tabular}{|c|c|c|c|c|c|c|}
\hline \multirow[t]{2}{*}{ Characteristic } & \multicolumn{3}{|c|}{ Univariate analysis } & \multicolumn{3}{|c|}{ Multivariate analysis } \\
\hline & $n$ & OR $(95 \% \mathrm{Cl})$ & $p$ value & $n$ & OR $(95 \% \mathrm{Cl})$ & $p$ value \\
\hline Overt DIC & 128 & & & & & \\
\hline Yes & & $3.00(1.40-6.42)$ & 0.005 & & & \\
\hline No & & 1.00 (Reference) & & & & \\
\hline Capillary leakage & 128 & & & 119 & & \\
\hline Yes & & $12.00(2.56-56.36)$ & 0.002 & & $6.30(1.13-35.22)$ & 0.036 \\
\hline No & & 1.00 (Reference) & & & 1.00 (Reference) & \\
\hline Creatine kinase (IU/L) & 126 & & & 119 & & \\
\hline$>500$ & & $7.70(3.32-17.86)$ & $<0.001$ & & $4.80(1.86-12.37)$ & 0.001 \\
\hline$\leq 500$ & & 1.00 (Reference) & & & 1.00 (Reference) & \\
\hline Serum sodium (mmol/L) & 128 & & & 119 & & \\
\hline$<135 \mathrm{mmol} / \mathrm{L}$ & & $5.35(2.44-11.74)$ & $<0.001$ & & $4.27(1.74-10.45)$ & 0.001 \\
\hline$\geq 135 \mathrm{mmol} / \mathrm{L}$ & & 1.00 (Reference) & & & 1.00 (Reference) & \\
\hline Total dose of antivenom (mL) & 121 & & & & & \\
\hline$>160$ & & $3.01(1.30-7.00)$ & 0.010 & & & \\
\hline$\leq 160$ & & 1.00 (Reference) & & & & \\
\hline
\end{tabular}


envenomation. In addition, hyponatremia was found to be an independent factor associated with AKI. Thus, evaluation of renal tubular function was performed among patients with snakebites from Viperidae who had normal renal function. At presentation, there were 128 patients who had been bitten by Viperidae or demonstrated the clinical syndrome of Viperidae envenoming with normal renal function. The subsequent electrolyte abnormalities observed in these patients included hyponatremia (45/128 patients, $35.2 \%)$, hypocalcemia (33/126 patients, $26.2 \%)$, hypokalemia (32/128 patients, $25.0 \%)$, hyperphosphatemia (21/126 patients, $16.7 \%)$, hypophosphatemia (12/126 patients, 9.5\%), metabolic acidosis (7/128 patients, $5.5 \%)$, hypernatremia (4/128 patients, $3.1 \%)$, hyperkalemia (4/128 patients, $3.1 \%)$, and hypercalcemia (2/126 patients, $1.6 \%)$.

Patients with hyponatremia had significantly higher urine sodium-to-creatinine ratio than those with serum sodium $\geq 135 \mathrm{mmol} / \mathrm{L}$ [median (IQR) 291.5 (139.7610.6) $\mathrm{mmol} / \mathrm{mmol}$ vs. $173.2(72.3-314.9) \mathrm{mmol} / \mathrm{mmol}$, $p<0.001]$. When these patients were subdivided into those who developed AKI during hospitalization and those who did not, 29 patients $(22.7 \%)$ with hyponatremia developed AKI, 21 (16.4\%) with serum sodium $\geq 135 \mathrm{mmol} / \mathrm{L}$ developed AKI, 16 (12.5\%) with hyponatremia did not develop AKI, and $62(48.4 \%)$ with serum sodium $\geq 135 \mathrm{mmol} / \mathrm{L}$ did not develop AKI. A significant difference in median urine sodium-to-creatinine ratio was observed across the groups (Kruskal-Wallis test, chi-squared $=21.285$, degrees of freedom $=3, p<0.001$ ). Post-hoc analysis using the Mann-Whitney $U$ test with Bonferroni correction indicated that the median [IQR] urine sodium-to-creatinine ratio of patients with hyponatremia who developed AKI during hospitalization (343.8 [154.0-817.3]) was significantly higher than that of patients with serum sodium $\geq 135 \mathrm{mmol} / \mathrm{L}$ who developed AKI during hospitalization (96.0 [35.7-219.7], $p<0.001)$ as well as that of patients with serum sodium $\geq 135 \mathrm{mmol} / \mathrm{L}$ who did not develop AKI (183.8 [101.3319.5], $p<0.001)$. However, urine sodium-to-creatinine ratio did not significantly differ between hyponatremic patients who developed AKI during hospitalization (343.8 [154.0-817.3]) and those who did not (198.9 [124.9-529.3], $p=0.083)$. The median [IQR] urine sodium-to-creatinine ratio of patients with hyponatremia who did not develop AKI (198.9 [124.9-529.3]) was significantly higher than that of patients with serum sodium $\geq 135 \mathrm{mmol} / \mathrm{L}$ who developed AKI during hospitalization (96.0 [35.7-219.7], $p=0.008$ ), but not significantly different from that of patients with serum sodium $\geq 135 \mathrm{mmol} / \mathrm{L}$ who did not develop AKI (183.8 [101.3-319.5], $p=0.189$ ) (Fig. 3a). There was a significant regression of urine sodium-to-creatinine ratio to serum sodium (urine sodium-to-creatinine ratio $=6175.05-42.97^{*}$ serum sodium, $\mathrm{F}_{(1127)}=36.075, p$ $<0.001)$, whereby $22.2 \%$ of variation could be explained by the regression line $\left(R^{2}=0.228\right.$, adjusted $\left.R^{2}=0.222\right)$. Serum sodium and urine sodium-to-creatinine ratio were also correlated $(r=-0.478, p<0.001)$ (Fig. 4a).

Patients with hypokalemia had significantly higher urine potassium-to-creatinine ratio than those with serum potassium $\geq 3.5 \mathrm{mmol} / \mathrm{L}$ [median (IQR) $2.2 \quad(0.9-4.3)$ $\mathrm{mmol} / \mathrm{mmol}$ vs. $0.3(0.2-0.5) \mathrm{mmol} / \mathrm{mmol}, p<0.001)$. When these patients were subdivided into those who developed AKI during hospitalization and those who did not, 13 patients $(10.1 \%)$ with hypokalemia had AKI, 37 (28.9\%) with serum potassium $\geq 3.5 \mathrm{mmol} / \mathrm{L}$ had AKI, 18 (14.1\%) with hypokalemia did not have AKI, and 60 (46.9\%) with serum potassium $\geq 3.5 \mathrm{mmol} / \mathrm{L}$ did not have AKI. A significant difference in median urine potassiumto-creatinine ratio was observed across the groups (Kruskal-Wallis test, chi-squared $=61.615$, degrees of freedom $=3, p<0.001$ ). Post-hoc analysis using the Mann-Whitney $U$ test with Bonferroni correction indicated that the median [IQR] urine potassium-tocreatinine ratio of patients with hypokalemia who developed AKI during hospitalization (3.8 [1.0-4.5]) was significantly higher than that of patients with serum potassium $\geq 3.5 \mathrm{mmol} / \mathrm{L}$ who developed AKI during hospitalization $(0.3[0.2-0.5], p<0.001)$ and that of patients with serum potassium $\geq 3.5 \mathrm{mmol} / \mathrm{L}$ who did not develop AKI $(0.3[0.2-0.5], p<0.001)$. However, urine potassium-to-creatinine ratio did not significantly differ between hypokalemic patients who developed AKI during hospitalization (3.8 [1.0-4.5]) and those who did not (2.1 $[0.9-3.2], p=0.242)$. The median [IQR] urine potassium-to-creatinine ratio of patients with hypokalemia who did not develop AKI (2.1 [0.9-3.2]) was significantly higher than that of patients with serum potassium $\geq 3.5 \mathrm{mmol} / \mathrm{L}$ who developed AKI during hospitalization $(0.3[0.2-0.5], p<0.001)$ and that of patients with serum potassium $\geq 3.5 \mathrm{mmol} / \mathrm{L}$ who did not develop AKI (0.3 [0.2-0.5], $p<0.001)$ (Fig. 3b). There was a significant regression of urine potassium-to-creatinine ratio to serum potassium (urine potassium-to-creatinine ratio $=4.72-0.92$ serum potassium, $\mathrm{F}_{(1127)}=35.056, p<$ 0.001 ), whereby $21.3 \%$ of variation could be explained by the regression line $\left(R^{2}=0.219\right.$, adjusted $\left.R^{2}=0.213\right)$. Serum potassium and urine potassium-to-creatinine ratio were also correlated $(r=-0.468, p<0.001)$ (Fig. 4b).

Serum magnesium and fractional excretion of magnesium were measured in 28 patients with hypokalemia. The median (IQR) of serum magnesium was 2.0 (1.82.2) $\mathrm{mg} / \mathrm{dL}$, with fractional magnesium excretion of 2.4 $(0.7-4.9) \%$. Of 28 patients with hypokalemia, hypomagnesemia was observed in 6 patients $(21.4 \%)$ and serum magnesium $\geq 1.7 \mathrm{mg} / \mathrm{dL}$ in 22 patients $(78.6 \%)$. The median (IQR) fractional excretion of magnesium was 6.4 

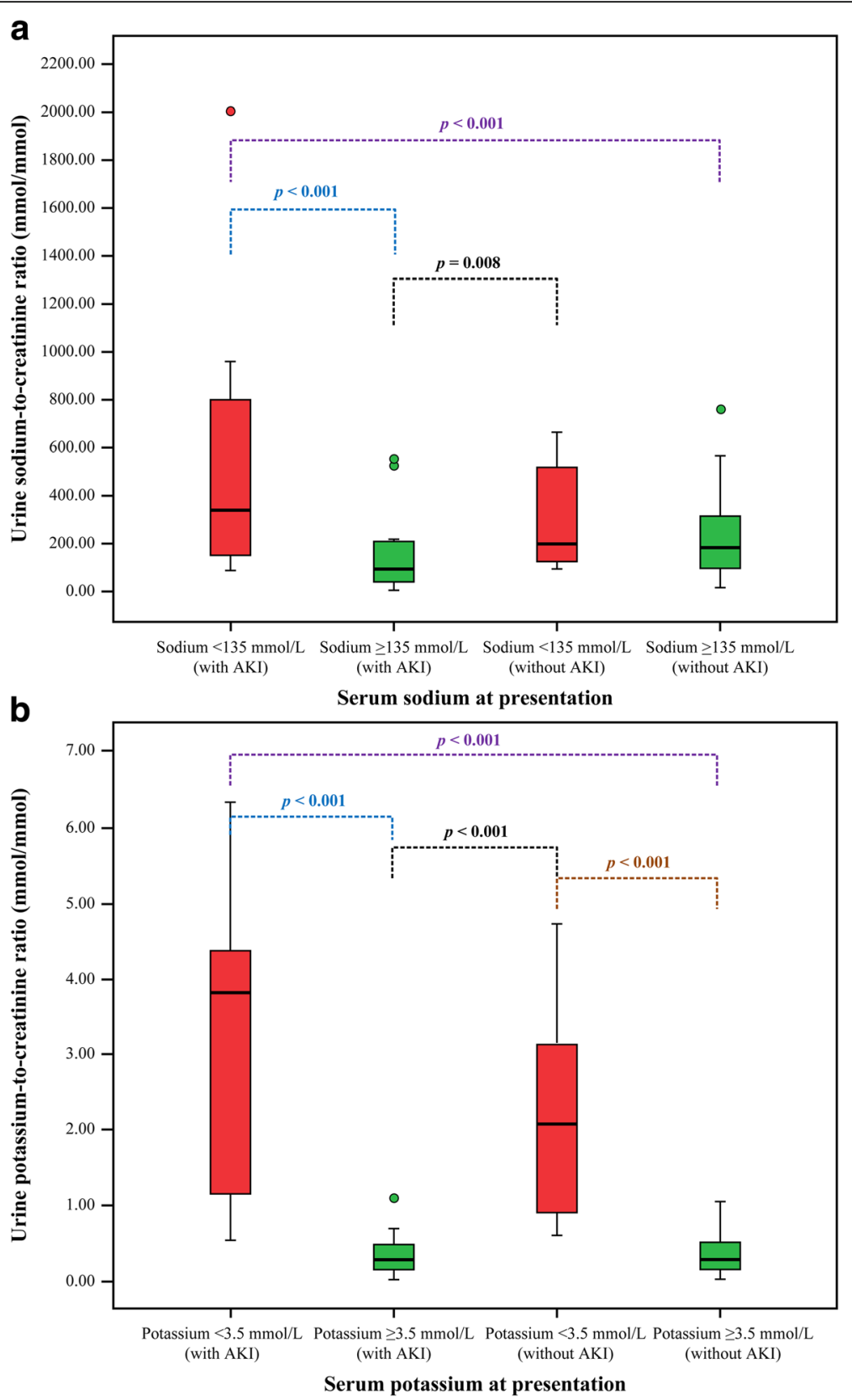

Fig. 3 Urine electrolyte-to-creatinine ratios and serum electrolytes among 128 patients with normal kidney function at presentation, stratified by the development of acute kidney injury during hospitalization. a Urine sodium-to-creatinine ratio ( $\mathrm{mmol} / \mathrm{mmol}$ ) among patients with serum sodium $<135 \mathrm{mmol} / \mathrm{L}$ and those with serum sodium $\geq 135 \mathrm{mmol} / \mathrm{L}$. b Urine potassium-to-creatinine ratio $(\mathrm{mmol} / \mathrm{mmol}$ ) among patients with serum potassium $<3.5 \mathrm{mmol} / \mathrm{L}$ and those with serum potassium $\geq 3.5 \mathrm{mmol} / \mathrm{L}$. Data are presented as box and whisker plots with median (horizontal line), interquartile range (box), and maximum value within 1.5 of interquartile range (whiskers)

(2.9-8.6)\% among patients with hypomagnesemia and $2.0(0.6-3.7) \%$ among those with serum magnesium $\geq 1.7 \mathrm{mg} / \mathrm{dL}(p=0.017)$. All patients with hypomagnesemia had fractional excretion of magnesium $>1.0 \%$. Of 22 patients with serum magnesium $\geq 1.7 \mathrm{mg} / \mathrm{dL}, 8$ (36.4\%) had fractional excretion of magnesium $<1 \%$, and 14 (63.6\%) had fractional excretion of magnesium $>1.0 \%$.
The median (IQR) fractional excretion of calcium was $0.8(0.2-4.0) \%$ among patients with hypocalcemia, and fractional excretion of phosphate was 5.4 (2.3-6.7)\% among patients with hypophosphatemia. No patients with hypophosphatemia had fractional excretion of phosphate $>15.0 \%$, and no patients with hypocalcemia had fractional excretion of calcium $>20.0 \%$. 


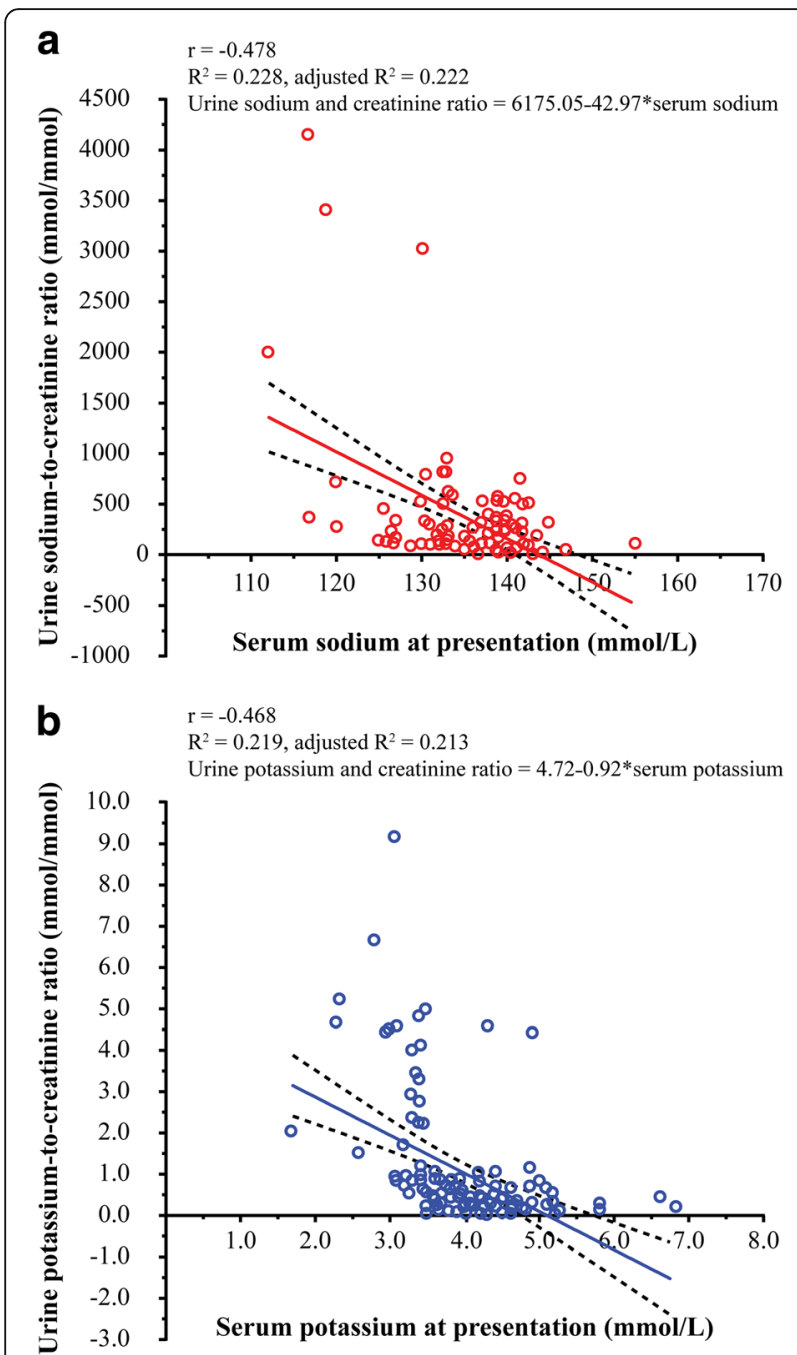

Fig. 4 Linear regression analysis of urine electrolyte-to-creatinine ratios and levels of serum electrolytes. a Urine sodium-to-creatinine ratio ( $\mathrm{mmol} / \mathrm{mmol}$ ) plotted against serum sodium ( $\mathrm{mmol} / \mathrm{L}$ ) levels among 128 patients with normal renal function. b Urine potassium-tocreatinine ratio $(\mathrm{mmol} / \mathrm{mmol})$ plotted against serum potassium $(\mathrm{mmol} / \mathrm{L})$ levels among 128 patients with normal renal function

\section{Discussion}

Snakebite envenomation is one of the common causes of cAKI in tropical countries, particularly in Southeast Asia $[1,2,4]$. The reported incidence of renal involvement with snakebite envenomation ranges from 1.4-28.0\% $[25,26]$. Renal involvement including proteinuria, hematuria, pigmenturia, and AKI is commonly observed among patients with snakebites from snakes of the family Viperidae [5-8]. Hemotoxic and myotoxic venom, particularly from Russell's viper and sea snake, are common causes of renal involvement [7, 8]. Similarly, in our study, the majority of patients were bitten by Russell's viper $(84.5 \%)$ and clinical renal manifestations were frequent among patients with snakebite envenomation, particularly reduced urine volume (49.6\%), renal tenderness $(44.2 \%)$, and urine protein-to-creatinine ratio $\geq 1$ (60.2\%). In Myanmar, proteinuria $>1 \mathrm{~g} / 24 \mathrm{~h}$ was previously reported in $50.0 \%$ of patients with Russell's viper bites [27] and hematuria in $35.0 \%$ of patents with hemotoxic snakebites or the occurrence of glomerulonephritis after snakebite envenomation [7, 8]. Previous reports showed that Russell's viper can cause both intravascular hemolysis and rhabdomyolysis, which is induced by phospholipase $A_{2}$ in snake venom $[7,8]$.

In our cohort, 140 patients (54.3\%) had sAKI according to the criteria of the KDIGO clinical practice guidelines [22]. In previous reports, sAKI was observed in $8.0-43.0 \%$ of patients with snakebite envenomation. The higher observed rate in the present study might be due to differences in criteria for AKI diagnosis, snake species, snake venom potency, and genetic variation of the victims [9-15, 19]. In our study, $62.9 \%$ of AKI patients had sAKI at presentation, and the rest (37.1\%) developed sAKI during hospitalization. Multivariate logistic regression analysis revealed the following parameters to be independently associated with sAKI: bites from snakes of the Viperidae family or presenting the clinical syndrome of Viperidae envenoming, leukocytosis, overt DIC, rhabdomyolysis, hyponatremia, glomerulonephritis, and duration from snakebite to receipt of antivenom $\geq 2 \mathrm{~h}$. Among patients bitten by Viperidae, the presence of hypotension, rhabdomyolysis, hyponatremia, glomerulonephritis, and duration from snakebite to receipt of antivenom $\geq 2 \mathrm{~h}$ were independently associated with sAKI at presentation. In addition, patients bitten by Viperidae who presented with capillary leakage, rhabdomyolysis, and hyponatremia were at increased risk for the development of sAKI during hospitalization. Previous studies reported similar factors associated with the sAKI, including receipt of antivenom $>2 \mathrm{~h}$ after snakebite, cellulitis, hypotension, and rhabdomyolysis $[9,10,13]$. A previous case series from Taiwan showed that early specific antivenom treatment within 3 to $6 \mathrm{~h}$ after snake envenoming could restore coagulation abnormalities in 1 to 2 days and was effective in reducing the severity of renal damage [28].

Our finding that leukocytosis was associated with sAKI is consistent with a previous experimental study in which leukocytosis was observed after injection of phospholipase $\mathrm{A}_{2}$ and metalloprotease from Russell's viper venom, which resulted in the elevation of interleukin-6, tumor necrosis factor- $\alpha$, and prostaglandin $E_{2}$ leading to increased renal vascular resistance and decreased blood pressure [29]. The observation of glomerular proteinuria and microscopic hematuria in our study suggested the occurrence of glomerulonephritis among patients with sAKI. A previous study from Myanmar also showed that $50 \%$ of patients with Russell's viper bites had proteinuria $>1 \mathrm{~g} / 24 \mathrm{~h}$ [27]. 
We found that a substantial number of patients with sAKI had hyponatremia, and patients with sAKI had significantly higher fractional excretion of sodium than those without SAKI, indicating the occurrence of renal tubular damage among patients with sAKI, which is consistent with a previous study from Myanmar reporting increased levels of beta-2 microglobulin and $\mathrm{N}$-acetyl glucosaminidase in urine among patients with sAKI from Russell's viper bites, also indicating renal tubular damage [27]. A previous report from India also showed that the renal pathology of AKI patients with Viperidae bites involved acute tubular necrosis, which might be due to the direct toxicity of the snake venom [30]. However, our patients with sAKI had significantly lower fractional excretion of urea $(28.5 \%)$ than those without sAKI $(42.3 \%)$, as well as serum urea-to-creatinine ratio $>20$ and urine specific gravity of 1.020 , indicating renal ischemia that might contribute to the development of sAKI. A previous study from Myanmar also showed that plasma renin concentrations were highly elevated among patients with sAKI from Russell's viper bites, suggesting the occurrence of renal ischemia in these patients [27]. A previous experimental study revealed massive fibrin deposition in glomerular capillaries, proximal and distal tubular necrosis, and hemolyzed red blood cell casts in the renal tubules of rats subjected to intravascular injection of snake venom, indicating that DIC contributed to renal ischemia in sAKI [31].

Furthermore, snake venom, particularly Viperidae snake venom containing proteolytic enzymes, can destruct the endothelium and basal membrane of capillaries. Thus, capillary permeability increases, albumins escape to the perivascular space, tissue oncotic pressure increases, and plasma oncotic pressure decreases, resulting in a shift of fluid balance from the intravascular to interstitial space, or capillary leakage. The decrease in intravascular volume may be sufficiently severe to compromise circulation, resulting in shock [32]. In cases of severe envenomation, snake venom can induce the release of autopharmacological vasoactive substances, particularly bradykinin, resulting in vasodilatation and myocardial depression, and consequently reduce myocardial contractility [32]. Therefore, our findings support the pathophysiology of sAKI as multifactorial, including hemodynamic changes, direct toxicity of snake venom, immunologic reaction and pigmenturia [33]. This pathophysiology would explain pathological observation of tubular necrosis, mesangiolysis, cortical necrosis, vasculitis, glomerulonephritis, interstitial nephritis, and renal infarction after snakebite envenomation [33].

In our study, $49.3 \%$ of patients with sAKI required RRT, which is within the range of previous reports $(15.0-55.0 \%)$ [9-11, 13]. The fatality rate was $19.3 \%$, which is also in the reported range (8.0-39.0\%) among patients with snakebite envenomation [9-11, 13, 14]. When clinical parameters and management of patients with sAKI were compared between patients who died and those who survived, patients who died were more likely to develop shock, have pulmonary complications, and receive management in the intensive care unit. However, the proportions of patients who received RRT and peritoneal dialysis as a dialysis method were similar between those who died and survived. The adequacy of dialysis determined by weekly Kt/V was less than 2.1 among AKI patients who died (median: 1.9, IQR: 1.1-3.0), but not among those who survived (median: 2.7, IQR: 2.2-3.9). However, there was no statistically significant difference between the groups, and it is probable that a small number of patients who died $(n=8)$ were evaluated for weekly Kt/V. According to the ISPD guideline for peritoneal dialysis in AKI, the target weekly $\mathrm{Kt} / \mathrm{V}$ of 3.5 provides outcomes comparable to that of daily hemodialysis. However, a target weekly Kt/V of 2.1 may be acceptable [23].

In our study, electrolyte abnormalities were common among patients with snakebite envenomation. Patients with snakebite envenomation by a member of the Viperidae family who had hyponatremia at presentation and developed AKI during hospitalization had a significantly higher urine sodium-to-creatinine ratio. Our findings also indicated a significant negative correlation between urine sodium-to-creatinine ratio and serum sodium $(r=-0.478)$, suggesting that hyponatremia among patients with Viperidae snakebites resulted from the renal tubular loss of sodium. Similarly, patients with hypokalemia who developed AKI during hospitalization had a significantly higher urine potassium-to-creatinine ratio. The significant negative correlation of urine potassium-to-creatinine ratio and serum potassium $(r=-0.468)$ suggests that hypokalemia among patients with Viperidae bites resulted from the renal tubular loss of potassium. Moreover, hypomagnesemia was observed in $21.4 \%$ of patients with hypokalemia, all of whom had urinary loss of magnesium. Our findings suggested that the renal tubular loss of electrolytes including sodium, potassium and magnesium might be caused by the direct toxicity of snake venom from the Viperidae family. A previous experimental study of Russell's viper venom demonstrated decreased renal tubular absorption of sodium in proximal and distal renal tubules resulting in increased fractional excretion of sodium due to $\mathrm{Na}+-\mathrm{K}+-$ ATPase activity inhibition of renal tubules in both the renal cortex and medulla [34].

None of the patients with hypocalcemia had fractional excretion of calcium $>20.0 \%$ and none of the patients with hypophosphatemia had fractional excretion of phosphate $>15.0 \%$, indicating extrarenal causes of hypocalcemia and hypophosphatemia. By contrast, hyperphosphatemia was more commonly observed compared to hypophosphatemia among patients with snakebite 
envenomation in our study. Thus, hypocalcemia might be caused by the process of intravascular thrombosis following the occurrence of DIC and rhabdomyolysis, and the occurrence of rhabdomyolysis would result in hyperphosphatemia among patients with snakebite envenomation [35, 36]. However, the possibility that hyperphosphatemia might occur secondary to AKI snake envenoming cannot be excluded [37].

\section{Strengths and limitations}

Our study has some limitations. First, all the data came from three academic tertiary care hospitals, which limits the generalizability of the study findings. Second, the snake could be identified in only $67.4 \%$ of cases. In case of unidentified snake bites, patient management relied on the clinical syndromes of snakebites defined in the WHO 2010 guidelines. However, our study was conducted as a prospective observational study in order to reduce bias, and the number of study patients achieved the required sample size for adequate statistical power. In addition, this study was the first to demonstrate the occurrence of impaired renal tubular function among patients with normal renal function who received bites from snake of the family Viperidae or having clinical syndrome of Viperidae envenoming.

\section{Conclusion}

Renal manifestations among patients with snake envenomation included reduce urine volume, renal tenderness, proteinuria, hematuria, electrolytes abnormalities, and AKI, and sAKI was a common and significant complication. The factors associated with sAKI included bites from snakes of the family Viperidae or presenting the clinical syndrome of Viperidae envenoming, duration from bite to receipt of antivenom $\geq 2 \mathrm{~h}$, leukocytosis, overt DIC, rhabdomyolysis, hyponatremia and presence of microscopic hematuria. Our findings support the hypothesis of multifactorial involvement in the pathogenesis of sAKI. After sustaining Viperidae bites, a significant number of patients with normal renal function developed proximal and distal renal tubular dysfunction. These findings might help clinicians to provide optimal management of patients who are at risk for the development of sAKI in order to reduce the incidence of cAKI in tropical countries in the future.

\section{Additional file}

Additional file 1: Table S1. Definitions of abnormal urine findings and electrolyte abnormalities. Table S2. Definitions of clinical parameters of snake envenoming according to the WHO 2010 guidelines. Table S3. Baseline characteristics and pre-hospital management among 258 adults with snakebite envenomation, Yangon, Myanmar, 2015-2016. Table S4. Clinical presentation among 258 adults with snakebite envenomation, Yangon, Myanmar, 2015-2016. Table S5. Laboratory parameters at presentation among 258 adults with snakebite envenomation, Yangon, Myanmar, 2015-2016. Table S6. Management and outcomes among 258 adults with snakebite envenomation, Yangon, Myanmar, 2015-2016. Table S7. Clinical parameters among 164 adults bitten by Viperidae or presenting the clinical syndrome of Viperidae (86 patients with acute kidney injury at presentation and 78 patients without acute kidney injury). Table S8. Laboratory parameters among 164 adults bitten by Viperidae or presenting the clinical syndrome of Viperidae (86 patients with acute kidney injury at presentation and 78 patients without acute kidney injury). Table S9. Management and outcomes among 164 adults bitten by Viperidae or presenting the clinical syndrome of Viperidae (86 patients with acute kidney injury at presentation and 78 patients without acute kidney injury). Table S10. Clinical parameters among 128 adults bitten by Viperidae or presenting the clinical syndrome of Viperidae (50 patients who developed acute kidney injury during hospitalization and 78 patients without acute kidney injury). Table S11. Laboratory parameters among 128 adults bitten by Viperidae or presenting the clinical syndrome of Viperidae (50 patients who developed acute kidney injury during hospitalization and 78 patients without acute kidney injury). Table S12. Management and outcomes among 128 adults bitten by Viperidae or presenting the clinical syndrome of Viperidae (50 patients who developed acute kidney injury during hospitalization and 78 patients without acute kidney injury). The supplementary tables provide additional data to help interpret the results of the study. (DOCX $92 \mathrm{~kb}$ )

\section{Abbreviations}

20WBCT: 20-min whole blood clotting test; AKI: Acute kidney injury; ALT: Alanine aminotransferase; aPTT: Activated partial thromboplastin time; ARDS: Acute respiratory distress syndrome; AST: Aspartate aminotransferase; CAKI: Community-acquired acute kidney injury; Cl: Confidence interval; DIC: Disseminated intravascular coagulation; ECG: Electrocardiography; Fe: Fractional excretion; HPF: high power field; ICU: Intensive care unit; IGH: Insein General Hospital; INR: International normalized ratio; IQR: Interquartile range; ISTH: International Society for Thrombosis and Haemostasis; NOGH: North Okkalapa General Hospital; OR: Odds ratio; PLT: Platelet; PT: Prothrombin time; RRT: Renal replacement therapy; SAKI: Snakebite related acute kidney injury; SBP: Systolic blood pressure; STROBE: Standards for the Reporting of Observation Studies in Epidemiology; TGH: Thingangyun Sanpya General Hospital; WBC: White blood cell; WHO: World Health Organization

\section{Acknowledgements}

The authors thank all patients who participated in this study, and the medical superintendents, staff members, and nurses from the Medical Wards and Renal Medical Department of Thingangyun Sanpya General Hospital, Insein General Hospital, and North Okkalapa General Hospital in Yangon, Myanmar. We are particularly grateful to Prof. Zaw Wai Soe (Rector of the University of Medicine 1), Prof. Aye Aung (Rector of the University of Medicine 2), Emeritus Prof. Nyunt Thein (University of Medicine 1), Dr. Thet Thet Mu (Director of Health Management Information System, Ministry of Health and Sports in Naypyitaw), Prof. Myo Lwin Nyein (Head, Department of Medicine, North Okkalapa General Hospital), Prof. Myat Mon (Head, Department of Pathology, Yangon General Hospital), and Prof. Mar Mar Kyi (Department of Medicine, Insein General Hospital) for their help and support in this study. We also thank Dr. Aye Aye Win (Senior Consultant Pathologist, Thingangyun Sanpya General Hospital), Dr. Swe Setk (Senior Consultant Pathologist, National Health Laboratory), Dr. Aye Thein Myint (Former First Assistant Physician, Thingangyun Sanpya General Hospital), Dr. Min Thein Naing (First Assistant Physician, Thingangyun Sanpya General Hospital), Daw Khin Win Kyi (Chief Technician, National Health Laboratory), Daw Myint Myint Win (Chief Technician, National Health Laboratory) and the technicians of the Biochemistry Department, National Health Laboratory, and Daw Than Than Nu (Laboratory Officer, Thingangyun Sanpya General Hospital and the technicians of Thingangyun Sanpya General Hospital for their help in performing this study. Furthermore, we thank Dr. Pratap Singhasivanon (Dean of Faculty of Tropical Medicine, Mahidol University, Associate Professor), Dr. Porntip Petchmitr (Deputy Dean of Faculty of Tropical Medicine, Mahidol University, Associate Professor), and the DAAD-Deutscher Akademischer Austauschdienst, German Academic Exchange Service Scholarship for providing their financial support of this study. 


\section{Funding}

This study was supported by the Faculty of Tropical Medicine, Mahidol University and DAAD-Deutscher Akademischer Austauschdienst (grant number A/13/93973). The funders had no role in the design of the study, data collection, data analysis, data interpretation, or writing the manuscript.

\section{Availability of data and materials}

The datasets used and/or analysed during the current study available from the corresponding author on reasonable request.

\section{Authors' contributions}

KA, VT, VD, SC, DS, and TS conceived and designed the study. KA, VT, VD, TS, and $V S$ performed the literature review. KA, CS, and KT screened patients and collected laboratory data. KA, VT, CS, VD, KT, and SC performed data collection. KA, VT, VD, DS, and VS performed statistical analysis and contributed to the writing of the manuscript. VT and VD revised the manuscript. All authors read and approved the final manuscript.

\section{Competing interests}

The authors declare that they have no competing interests.

\section{Consent for publication}

Not applicable

\section{Ethics approval and consent to participate}

This study was approved by the Ethics Committee of the Faculty of Tropica Medicine, Mahidol University, Bangkok, Thailand, and the Ethics Committee of the University of Medicine 2, Yangon, Myanmar. Patients with snakebites who received treatment at three tertiary hospitals, namely Thingangyun Sanpya General Hospital, Insein General Hospital, and North Okkalapa General Hospital in Yangon, Myanmar between March 2015 and June 2016 and met the study criteria were approached for participation. Before participation in this study, written informed consent was obtained from all patients and their parents/guardians, in the case of patients under 18 years of age. In the case of deceased persons, patients and their parents/guardians, in the case of patients under 18 years of age, gave written informed consents before they died. Data were anonymized before analyses.

\section{Publisher's Note}

Springer Nature remains neutral with regard to jurisdictional claims in published maps and institutional affiliations.

\section{Author details \\ ${ }^{1}$ Department of Clinical Tropical Medicine, Faculty of Tropical Medicine, Mahidol University, Bangkok 10400, Thailand. ${ }^{2}$ Medical Ward (I), 1000 Bedded Hospital, Naypyitaw 15011, Myanmar. ${ }^{3}$ Department of Rheumatology, University of Medicine 1, Lanmadaw, Yangon 11131, Myanmar. ${ }^{4}$ Department of Nephrology, University of Medicine 1, Lanmadaw, Yangon 11131, Myanmar. ${ }^{5}$ Information Technology Unit, Faculty of Tropical Medicine, Mahidol University, Bangkok 10400, Thailand. 'Division of Nephrology, Phramongkutklao Hospital, Bangkok 10400, Thailand. ${ }^{7}$ Division of Nephrology, Department of Medicine, Faculty of Medicine, Chulalongkorn University and King Chulalongkorn Memorial Hospital, Bangkok 10330, Thailand. ${ }^{8}$ Queen Saovabha Memorial Institute, Thai Red Cross, Bangkok 10330, Thailand.}

Received: 8 December 2016 Accepted: 9 March 2017

Published online: 16 March 2017

\section{References}

1. Jha V, Chugh KS. Community-acquired acute kidney injury in Asia. Semin Nephrol. 2008;28:330-47.

2. Jha V, Parameswaran S. Community-acquired acute kidney injury in tropical countries. Nat Rev Nephrol. 2013;9:278-90.

3. Chawla LS, Eggers PW, Star RA, Kimmel PL. Acute kidney injury and chronic kidney disease as interconnected syndromes. N Engl J Med. 2014;371:58-66.

4. Kasturiratne A, Wickremasinghe AR, de Silva N, Gunawardena NK, Pathmeswaran A, Premaratna $R$, et al. The global burden of snakebite: a literature analysis and modelling based on regional estimates of envenoming and deaths. Plos Med. 2008:5:e218.
5. Chippaux JP. Snake-bites: appraisal of the global situation. Bull World Health Organ. 1998;76:515-24

6. World Health Organization (WHO). Guidelines for the management of snake-bites in South-East Asia. New Delhi: WHO; 2010.

7. Kanjanabuch T, Sitprija V. Snakebite nephrotoxicity in Asia. Semin Nephrol. 2008:28:363-72.

8. Sitprija V. Snakebite nephropathy. Nephrology (Carlton). 2006;11:442-8.

9. Pinho FM, Zanetta DM, Burdmann EA. Acute renal failure after Crotalus durissus snakebite: a prospective survey on 100 patients. Kidney Int. 2005;67:659-67.

10. Athappan G, Balaji MV, Navaneethan U, Thirumalikolundusubramanian P. Acute renal failure in snake envenomation: a large prospective study. Saudi J Kidney Dis Transpl. 2008;19:404-10.

11. Danis R, Ozmen S, Celen MK, Akin D, Ayaz C, Yazanel O. Snakebite-induced acute kidney injury: data from Southeast Anatolia. Ren Fail. 2008;30:51-5.

12. Paul J, Dasgupta S. Early prediction of acute kidney injury by clinical features of snakebite patients at the time of hospital admission. N Am J Med Sci. 2012;4:216-20.

13. Dharod MV, Patil TB, Deshpande AS, Gulhane RV, Patil MB, Bansod YV. Clinical predictors of acute kidney injury following snake bite envenomation. N Am J Med Sci. 2013;5:594-9.

14. Harshavardhan L, Lokesh AJ, Tejeshwari HL, Halesha BR, Metri SS. A study on the acute kidney injury in snake bite victims in a tertiary care centre. J Clin Diagn Res. 2013;7:853-6.

15. Albuquerque $P L$, Silva Jr GB, Jacinto CN, Lima JB, Lima CB, Amaral YS, et al. Acute kidney injury after snakebite accident treated in a Brazilian tertiary care centre. Nephrology (Carlton). 2014;19:764-70.

16. Silveira PV, Nishioka S, De A. South American rattlesnake bite in a Brazilian teaching hospital. Clinical and epidemiological study of 87 cases, with analysis of factors predictive of renal failure. Trans R Soc Trop Med Hyg. 1992;86:562-4.

17. Nishioka Sde A, Silveira PV. A clinical and epidemiologic study of 292 cases of lance-headed viper bite in a Brazilian teaching hospital. Am J Trop Med Hyg. 1992;47:805-10.

18. Khin M, Nyunt T, Oo NT, Hla Y. Prognostic indicators in patients with snakebite: analysis of 2-year data from township hospital in central Myanmar. WHO South-East Asia J Public Health. 2012;1:144-50.

19. Thein-Than, Tin-Tun, Hla-Pe, Phillips RE, Myint-Lwin, Tin-Nu-Swe, Warrell DA. Development of renal function abnormalities following bites by Russell's vipers (Daboia russelii siamensis) in Myanmar. Trans R Soc Trop Med Hyg. 1991:85:404-9.

20. von Elm E, Altman DG, Egger M, Pocock SJ, Gøtzsche PC, Vandenbroucke JP, et al. The Strengthening the Reporting of Observational Studies in Epidemiology (STROBE) statement: guidelines for reporting observational studies. Lancet. 2007:370:1453-7.

21. Levi M, Toh $\mathrm{CH}$, Thachil J, Watson HG. Guidelines for the diagnosis and management of disseminated intravascular coagulation. British Committee for Standards in Haematology. Br J Haematol. 2009;145:24-33.

22. Palevsky PM, Liu KD, Brophy PD, Chawla LS, Parikh CR, Thakar CV, et al KDOQI US commentary on the $2012 \mathrm{KDIGO}$ clinical practice guideline for acute kidney injury. Am J Kidney Dis. 2013;61:649-72.

23. Cullis B, Abdelraheem M, Abrahams G, Balbi A, Cruz DN, Frishberg Y, et al. Peritoneal dialysis for acute kidney injury. Perit Dial Int. 2014;34:494-517.

24. Leviton AE, Zug GR, Vindum JV, Wogan GOU. Handbook to the dangerously venomous snakes of Myanmar. San Francisco: California Academy of Sciences; 2008. https://www.researchgate.net/publication/263382509_ Handbook_to_the_Dangerously_Venomous_Snakes_of_Myanmar. Accessed 15 Aug 2013.

25. Chugh KS, Pal Y, Chakravarty RN, Datta BN, Mehta R, Sakhuja V, et al. Acute renal failure following poisonous snakebite. Am J Kidney Dis. 1984;4:30-8.

26. Karthik S, Phadke KD. Snakebite-induced acute renal failure. A case report and review of the literature. Pediatr Nephrol. 2004;19:1053-4.

27. Tin-Nu-Swe, Tin-Tun, Myint-Lwin, Thein-Than, Tun-Pe, Robertson Jl, Leckie BJ, Phillips RE, Warrell DA. Renal ischaemia, transient glomerular leak and acute renal tubular damage in patients envenomed by Russell's vipers (Daboia russelii siamensis) in Myanmar. Trans R Soc Trop Med Hyg. 1993;87: 678-81.

28. Hung DZ, Yu YJ, Hsu CL, Lin TJ. Antivenom treatment and renal dysfunction in Russell's viper snakebite in Taiwan: a case series. Trans R Soc Trop Med Hyg. 2006;100:489-94.

29. Mitrmoonpitak C, Chulasugandha P, Khow O, Noiprom J, Chaiyabutr N, Sitprija $\mathrm{V}$. Effects of phospholipase A2 and metalloprotease fractions of 
Russell's viper venom on cytokines and renal hemodynamics in dogs. Toxicon. 2013;61:47-53.

30. Vijeth SR, Dutta TK, Shahapurkar J. Correlation of renal status with hematologic profile in viperine bite. Am J Trop Med Hyg. 1997;56:168-70.

31. Burdmann EA, Woronik V, Prado EB, Abdulkader RC, Saldanha LB, Barreto OC, et al. Snakebite-induced acute renal failure: an experimental model. Am J Trop Med Hyg. 1993;48:82-8.

32. Adukauskienè $D$, Varanauskienè E, Adukauskaitè A. Venomous snakebites. Medicina (Kaunas). 2011;47:461-7.

33. Sitprija V. Animal toxins and the kidney. Nat Clin Pract Nephrol. 2008;4:616-27.

34. Chaiyabutra N, Vasaruchaponga T, Chanhomea L, Rungsipipatb A, Sitprija V. Acute effect of Russell's viper (Daboia siamensis) venom on renal tubular handling of sodium in isolated rabbit kidney. Asian Biomed. 2014;8:195-202

35. Chavez LO, Leon M, Einav S, Varon J. Beyond muscle destruction: a systematic review of rhabdomyolysis for clinical practice. Crit Care. 2016;20:135.

36. Bosch X, Poch E, Grau JM. Rhabdomyolysis and acute kidney injury. N Engl J Med. 2009:361:62-72.

37. Claure-Del Granado R, Bouchard J. Acid-base and electrolyte abnormalities during renal support for acute kidney injury: recognition and management. Blood Purif. 2012;34:186-93.

Submit your next manuscript to BioMed Central and we will help you at every step:

- We accept pre-submission inquiries

- Our selector tool helps you to find the most relevant journal

- We provide round the clock customer support

- Convenient online submission

- Thorough peer review

- Inclusion in PubMed and all major indexing services

- Maximum visibility for your research

Submit your manuscript at www.biomedcentral.com/submit
Biomed Central 